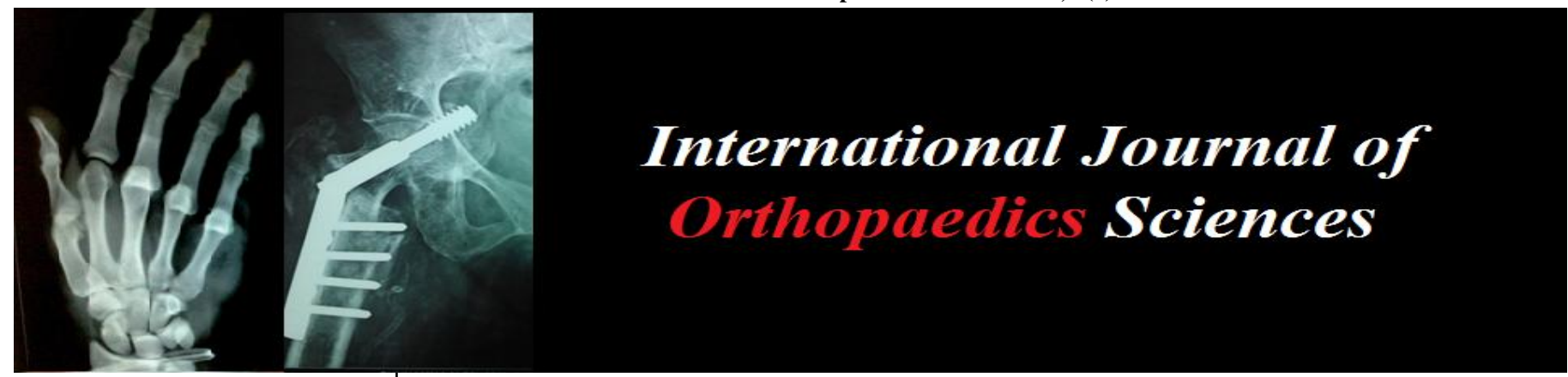

ISSN: $2395-1958$

IJOS 2018; 4(2): 334-336

(C) 2018 IJOS

www.orthopaper.com

Received: 26-02-2018

Accepted: 31-03-2018

Dr. Deepak K Aher

Senior Resident, Orthopaedics, Gandhi Medical College, Bhopal, MP, India

Dr. Shailandra Kumar Pandey Resident, Orthopaedics, GMC Bhopal, MP, India

Dr. Saurabh Alawa

Resident, Orthopaedics, GMC

Bhopal, MP, India

Dr. Abhishek Pathak

Associate Professor,

Orthopaedics, GMC Bhopal, MP
Correspondence

Dr. Deepak K Aher

Senior Resident, Orthopaedics, Gandhi Medical College, Bhopal, MP, India

\section{Evaluation of functional outcome of tension band wiring in olecranon fractures and factors affecting the overall functional outcome}

\author{
Dr. Deepak K Aher, Dr. Shailandra Kumar Pandey, Dr. Saurabh Alawa \\ and Dr. Abhishek Pathak
}

DOI: https://doi.org/10.22271/ortho.2018.v4.i2e.50

Abstract

Aim: The aim of this study is to evaluate the functional outcomes of olecranon fractures treated with tension band wiring and factors affecting it.

Materials and methods: this study consisted of 30 patients with olecranon fractures aged between 18-48 years. Minimum follow up of 1 year was done. Results were assessed radiologically and clinically using mayo elbow performance score. Also some factors that affected the outcome were also noted.

Result: mean postoperative range of motion after tension band wiring was $108^{\circ}$ (range $80^{\circ}-140^{\circ}$ ). Functional outcome was excellent in 18, good in 8, fair in 2 and poor in 2 according to the Mayo elbow performance score (MEPS). The average time taken for union was 7 weeks (range 4-12 weeks). Young men with non comminuted, transverse facture, with small proximal fragment of olecranon and those compliant to early physiotherapy showed better outcomes

Conclusion: Tension band wiring is effective method of fixation in terms of union and elbow movements. Factors like age sex compliance to physiotherapy and type of fracture surely affect the final functional outcomes.

Keywords: Tension band wiring, MEPS

\section{Introduction}

Olecranon fracture is an intraarticular fracture, with loss in the extension mechanism of elbow; so surgery is generally the treatment ${ }^{[1]}$. Adequate reduction and rigid fixation are the primary aim of operation, thus, allowing early mobilization and reduce morbidity due to stiffness ${ }^{[2]}$. if not treated adequately, the olecranon fracture may end up with restriction of motion as it is intraarticular ${ }^{[3-5]}$. Weber and Vasey in 1963 introduced tension band wiring for treatment of olecranon fractures ${ }^{[2]}$. the principle of tension band wiring is conversion of distraction forces on the outer cortex of the ulna during elbow flexion to compression forces on the articular surface of the olecranon at the fracture site ${ }^{[6]}$

The main aim of this study was to assess the functional outcome of elbow after tension band wiring of fracture olecranon and to assess the factors that may affect the final results

\section{Materials and Methods}

Our prospective study included 30 patients operated at a tertiary care centre for olecranon fracture from January 2015 To January 2017. The mean age was 30 years and minimum follow up was 1 year

\section{Inclusion Criteria}

1. isolated olecranon fracture

2. age $>18$ years

3. trauma $<10$ days of admission 


\section{Exclusion Criteria}

1. Polytrauma Patients

2. Olecranon fracture with elbow dislocation, terrible triad injury, multiple fractures

When patient were admitted, informed consent taken for operation and tension band wiring done in all with $2 \mathrm{~K}$ wires (figure 1,2). The limb elevation in posterior slab for the first two days was done. Arm pouch applied after subsidence of swelling with this, gradual flexion extension. Exercises were started as tolerated by the patient. Follow up was at done at 4weeks, 8 weeks 6 months and 1 year. radiological assessment was done with $\mathrm{x}$ rays and functional assessment was done using Mayo elbow performance score( MEPS). The Mayo Elbow Performance Index (MEPI) consists of four domains: pain (one item, maximum score 45 points), range of motion (20 points), stability (one item, 10 points), and function ( 5 items, 5 points each). Each domain is transformed into a 100-point scale with higher score representing better outcome ${ }^{[7]}$. maximum possible score can be 100 , and the results are graded as excellent for scores $>90$; good for scores 75-89; fair for 60-74 and poor for scores less than 60 .

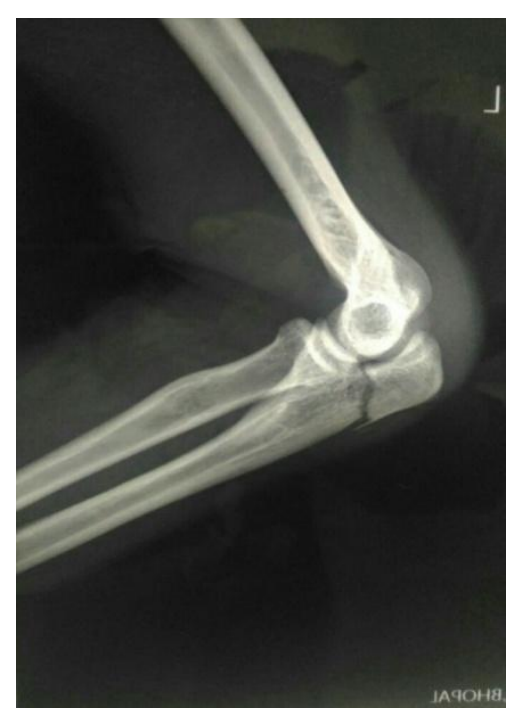

Fig 1: fracture olecranon

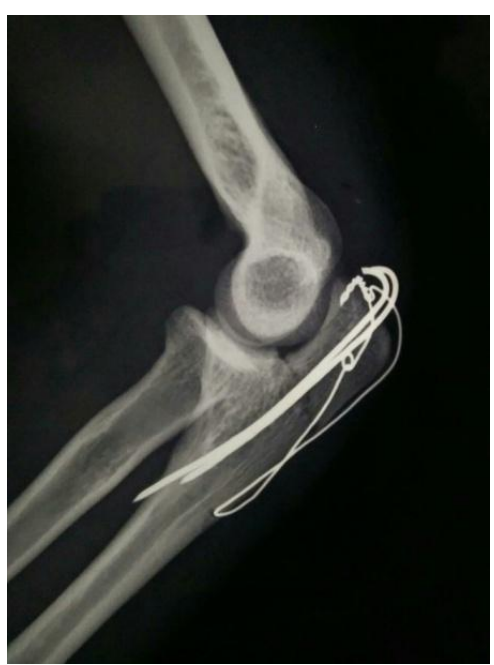

Fig 2: tension band wiring

\section{Results}

In our study of 30 patients, 26 were males and 4 were females. Mean Age of the patient was 30 years (range 18 years to 48 years). There were 24 right sided fracture $(80 \%)$. There were no bilateral cases. 22 patients $(73.33 \%)$ had transverse fractures and $8(26.6 \%)$ had oblique fractures. Comminuted fractures were seen in 4 patients. Most common mode of injury was fall on ground $(90 \%)$, other being assault $(10 \%)$. All the cases were operated in 1-7 days following injury. Mean operative time of tension band wiring was 45 minutes (range 30 minutes to 60 minute). The mean range of motion after 1 year was 108 degrees (range 80- 140 degrees). Average radiological union was seen at 7 weeks (range 4 weeks to 12 weeks). Hardware impingement was seen in 6 cases at 1 year follow up, infection was seen in 2 patients. The overall average MEPS was 88 (range 82-98). Functional outcome was as depicted in table 1

Table 1: functional outcome

\begin{tabular}{|c|c|}
\hline Functionl outcome & No of patients \\
\hline Excellent & 18 \\
\hline Good & 8 \\
\hline Fair & 2 \\
\hline Poor & 2 \\
\hline
\end{tabular}

Out of the 18 excellent outcomes, 14 were males, all 18 were compliant to early physiotherapy (figure 3, 4), 16 had transverse fractures and 14 were $=<30$ years of age. All the 2 poor outcome had comminuted fractures and large proximal fragment of olecranon.

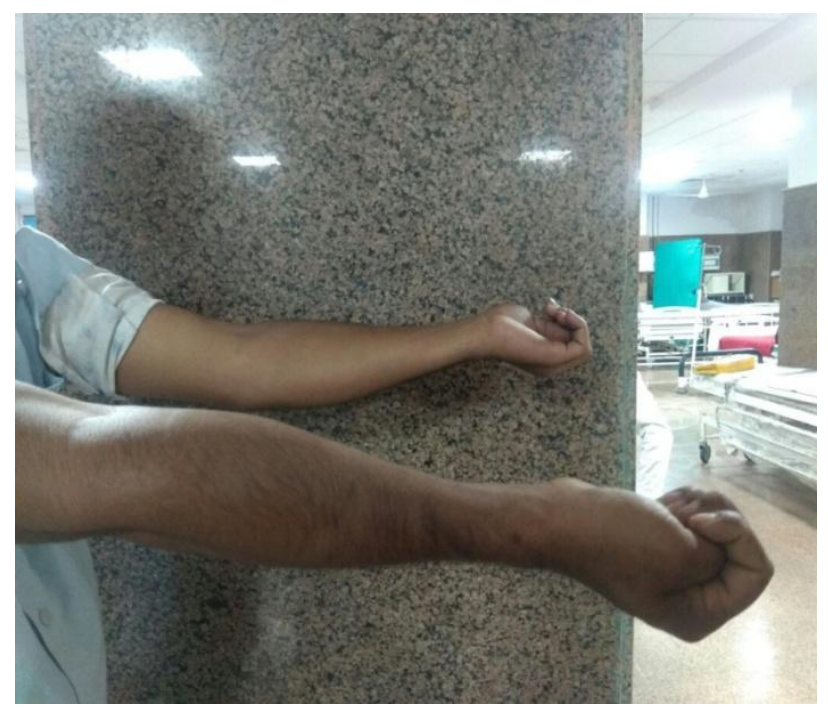

Fig 3: follow up at 1 year: extension (left elbow)

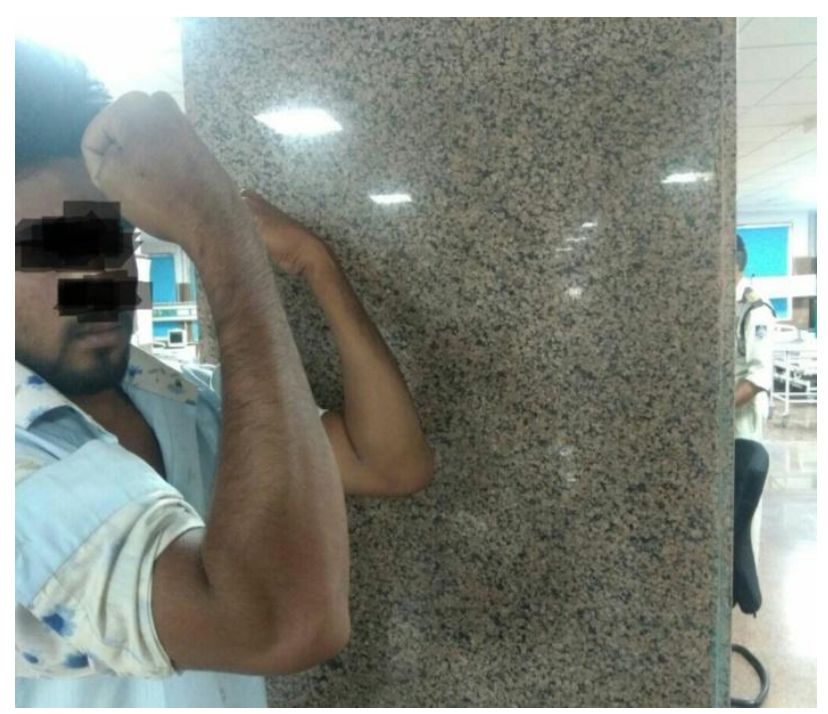

Fig 4: follow up at 1 year: flexion ( left elbow) 


\section{Discussion}

To achieve early movements and to prevent complications like traumatic arthritis and joint stiffness we need a perfect anatomical reduction in intraarticular fractures like fractures of the olecranon. Tension band wiring converts tensile forces to compressive forces at the fracture site and thus provides strength of fixation.

In our study, olecranon fractures showed a higher prevalence among men i.e. 26(86.66\%) and female patients being 4(13.33\%). Rommens et al. [1] in his study also reported increased prevalence in male. In 1992, Hume and Wiss and in 1993 fan et al. Reported that union was achieved in about 14 weeks ${ }^{[8,9]}$. In 1987 Wolfgang g et al. Postulated that a stable fixation with a high union rate is usually provided by tensionband wiring for simple non-comminuted transverse olecranon fractures ${ }^{[10]}$. In our study hardware impingement was seen in 6 patients $(20 \%)$ and infection in $2(6.66 \%)$. Macko et al., Yi Ming Ren et al., Matar he et al. reported similar complications as reported in our study $(5,11,12)$. An incidence of non-union of about $1 \%$ was reported by Papagelopoulosn and Morrey in 1994 [13]. Evaluation of functional outcome was done according to Mayo Elbow Performance Scoring System (MEPS). Maximum score is 100 and functional outcome is graded as excellent for scores $>90$; good for scores 75-89; fair for 60-74 and poor for scores less than 60. In our study we had excellent results in 18 patients $(60 \%)$ better than that of Ahmed et al. (40\%).however good results were obtained in $26.66 \%$ of cases in our study which is Less than that obtained by Ahmed et al. ${ }^{[14]}$. Mean range of motion in our study was comparable to other studies like that by Chalidis et al. and Lindenhovius et al. And somewhat superior to that of Van Der Linden et al. In terms of range of motion ${ }^{[15-17]}$. In his study of 52 patients, Rettig et al. reported ulnar nerve palsy in only 1 that too resolved spontaneously ${ }^{[18]}$. In our study, we had no patient with ulnar nerve palsy.

\section{Conclusion}

Tension band wiring is an effective method for treatment of transverse olecranon fractures and yields excellent to good functional outcomes in good percentage. Radiological union too is achieved in satisfactory duration. Young males, transverse fractures, smaller proximal fragment of olecranon and those compliant to early physiotherapy show good functional outcomes.

\section{References}

1. Rommens PM, Schneider RU, Reuter M. Functional results after operative treatment of olecranon fractures. ActaChir Belg. 2004; 104(2):191-7.

2. Pun WK, Chow SP, So YC, Luk KD, Ip FK, Chan KC et al. A prospective study on 284 digital fractures of the hand. J Hand Surg [Am]. 1989; 14:474-481.

3. Campbell's operative Orthopaedics, 13th Edition.

4. Rockwood and Green's fracture in adults, 8th Edition.

5. Macko D, Szabo RM. Complications of tension-band wiring of olecranon fractures. J Bone Joint Surg Am. 1985; 67:1396-1401.

6. Schneider MM, Nowak TE, Bastian L, Katthagen JC, Isenberg J, Rommens PM et al. Tension band wiring in olecranon fractures: the myth of technical simplicity and osteosynthetical perfection. Int Orthop. 2014; 38:847-855

7. Morrey BF, An KN, Chao EYS. Functional evaluation of the elbow. In: The Elbow and Its Disorders. 2nd edition. Edited by Morrey BF. Philadelphia: WB Saunders, 1993, 86-89.
8. Hume MC, Wisse DA. Olecranon fractures-a clinical and radiographic comparison of tension band wiring and plate fixation. Clin Orthop Relat Res. 1991, 229-35.

9. Fan $\mathrm{G}, \mathrm{Wu} \mathrm{CC}$, Shin $\mathrm{CH}$. Olecranon fractures with tension band wiring techniques - comparison among three different configurations. Chang Gung Medical Journal. 1993; 16:231-238.

10. Wolfgang G, Burke F, Bush D. Surgical treatment of displaced olecranon fractures by tension band wiring technique. Clin Orthop. 1987; 224:192-204

11. Yi-Ming Ren, Hu-Yun Qiao. Efficacy and safety of tension band wiring versus plate fixation in olecranon fractures: a systematic review and meta-analysis. Journal of Orthopaedic Surgery and Research. 2016; 11:137.

12. Matar HE, Ali AA, Buckley S, Garlick NI, Atkinson HD. Surgical interventions for treating fractures of the olecranon in adults. Cochrane Database of Systematic Reviews, 2014, 11.

13. Papagelopoulos PJ, Morrey BF. Treatment of nonunion of olecranon fractures. J Bone Joint Surg. 1994; 76B:627635.

14. Ahmed AR, Sweed T, Wanas A. The role of cancellous screw with tension band fixation in the treatment of displaced Olecranon fractures, a comparative study. European Journal of Orthopaedic Surgery \& Traumatology. 2008; 18:571-576.

15. Chalidis BE, Sachinis NC, Samoladas EP, Dimitriou CG, Pournaras JD. Is tension band wiring technique the -gold standard for the treatment of olecranon fractures? A long term functional outcome study. Journal of orthopaedic surgery andresearch. 2008; 3:9.

16. Lindenhovius ALC, Brouwer KM, Doornberg JN. Longterm outcome of operatively treated fracture-dislocations of the olecranon. J Orthop Trauma. 2008; 22:325-31.

17. Van der Linden SC, van Kampen A, Jaarsma RL. K-wire position in tension-band wiring technique affects stability of wires and long-term outcome in surgical treatment of olecranon fractures. Journal of shoulder and elbow surgery/American Shoulder and Elbow Surgeons. 2012; 21:405-411.

18. Rettig AC, Waugh TR, Evanski PM. Fracture of the olecranon: a problem of management. J Trauma. 1979; 19:23-8. 